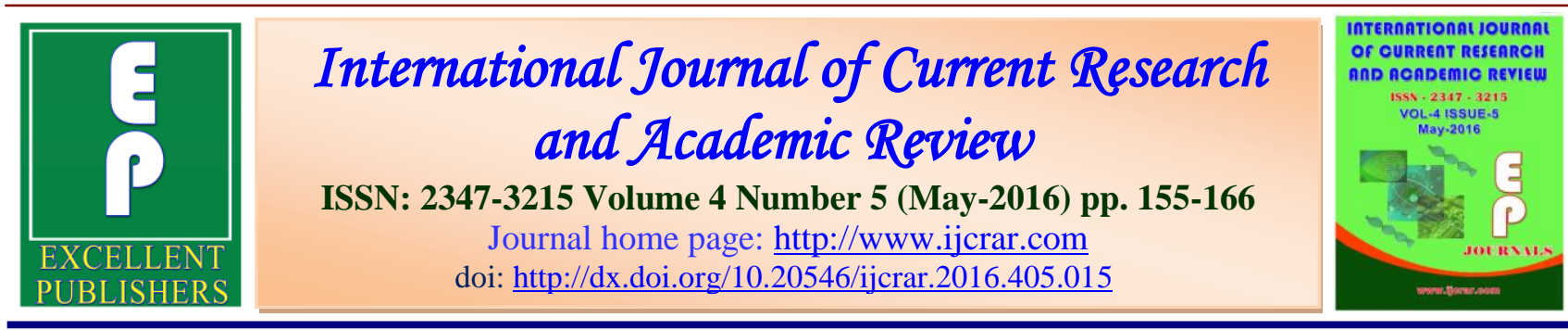

\title{
Work Related Health Disorders of Female Agricultural Workers Correlated with Sawing and Ploughing in Bengal: An Ergonomic Profile
}

\section{Sugata Das ${ }^{1}$, Anandi Bagchi ${ }^{2}$, Somnath Gangopadhay ${ }^{3}$ and Subrata Ghosh ${ }^{4 *}$}

${ }^{1}$ Research Scholar, Department of Physiology, CU, 92, APC Road, Kolkata, West Bengal, India

${ }^{2}$ Assistant Professor, Jhargram Raj College, Jhargram, West Midnapore, West Bengal, India ${ }^{3}$ Professor, University of Calcutta, 92, APC Road, Kolkata, West Bengal, India

${ }^{4}$ Associate Professor, Department of Physiology, Hooghly Mohsin College, Chinsurah. Hooghly, West Bengal, India

*Corresponding author

\section{KEYWORDS}

Agriculture, bloodglucose, MSD, occupational safety, Ergonomic hazards.

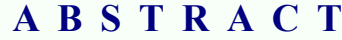

Agriculture is one of the three most hazardous sectors of activity, both in industrialized and developing countries. Due to lack of mechanization mostly female agriculture workers are very much prone to suffer in Work related Disorders (WD) and Work related musculoskeletal related disorders (WMSD). Defined what kind of stress factor they were passing on and what was the gradation of stress and quantify it. Also recommended the suitable technique to reduce the problem faced by the female workers and formulated some principle, some protocol or some guideline to reduce their everyday stress. The study was a double blind study, conducted in Golagori village, Khannan, Hooghly amongst female farmers associated with potato and paddy production, compared with the same parameters from control subjects who are involved with sedentary forms of work for equal days. All general physical parameters, dynamic lung function parameters, ergonomic posture analyses and biochemical assessment of blood sugar were performed by standardized procedure. Only systolic blood pressure was found to be higher for these females. Blood glucose level of subjects group was found to be lower than their respective clinical values. RULA, REBA, OWAS, SI Index values were found to be much higher for those female workers. Due to awkward posture during sawing and ploughing they faced ergonomic and musculoskeletal disorders. Also presence of low blood-glucose level, menstrual irregularities, polycystic ovaries and early menopause had also been described. performance. This study presents new information on quality of work life and work performance of university staff in a Ghanaian context. 


\section{Introduction}

Agriculture is one of the three most hazardous sectors of activity, both in industrialized and developing countries. According to estimates from International Labour Organization (ILO), some 170,000 agricultural workers are killed each year. This means that workers in agriculture run at least twice the risk of dying on the job as compared with workers in other sectors. Millions of agricultural workers are seriously injured in workplace accidents with agricultural machinery or poisoned by pesticides and other agrochemicals. Furthermore, due to the widespread underreporting of deaths, injuries and occupational diseases in agriculture, the real picture of the occupational health and safety of farm workers is likely to be worse than what official statistics indicate. Regarding this statistics, only male agriculture workers are mostly counted and painful condition of the women labourers remain silent, neglected and marginalized.

In developing countries, the great majority of women workers in agriculture are in subsistence farming, plantation, sapling, weeding, winnowing, self-employed or working as unpaid family

members. Agricultural labourers in West Bengal are being widely scattered over approx 41 thousand villages, while in India, it is being 5.6 lakh villages. Agricultural labourers, especially in smaller villages away from towns and cities, are generally unskilled workers. Chronic conditions due to noise, vibration, and low exposure to dusts or pesticides are more difficult to evaluate due to their long-term effects and uncertain symptoms. Workers are thus deprived of proper treatment and appropriated preventive measures. This situation is becoming particularly serious with rapid technological changes in agricultural production and with an increasing use of hazardous substances (Vetrivel et al., 2013). There is urgent need to mechanize the agricultural operations so that wastage of labour-force is avoided and farming is made convenient and efficient. Due to lack of mechanization, mostly female agriculture workers are very much prone to suffer in Work disorders (WD) and Work related musculoskeletal disorders (WMSD). According to 2011 census in India, female ratio is 940 per 1000 male. About one-third of women do more work than men, is a matter of common knowledge, while their work remains largely under-recorded, hence the real issue, is more serious. In India, women-workers constitute about one-fifth of the total work-force in the overall economic activity. The workers constituted 39.79 percent of the total population whereas the ratio of female workers was 25.51 percent in comparison to male counterpart. The ratio of female workers in the rural areas is $30.02 \%$ whereas in the urban areas it is 15.44 percent. (Ministry of Labour, Chandigarh, 2012)

The heavy manual labour, performed by malnourished women, often under subhuman working and living conditions, cause a number of health problems of which musculoskeletal problems are one of the commonest problems of women in unorganized sector. Repetitive trauma is often the cause of a variety of musculoskeletal and neurological disorders in women. Work related musculoskeletal disorders (WMSD) of the neck and shoulders and upper limbs are also known as cumulative trauma disorders (CTD). Evidences from a number of studies suggest that all these disorders principally result from constrained/awkward working posture, monotonous and repetitive work and psychological stress. Even in mechanical jobs, most of the tools, machines and work stations have been designed for average 
male and are unsuitable for women from an ergonomic angle. More research is needed to explore the relationships between injury to agricultural women and the social, cultural, physiological and economic aspects of the work environment. (World Bank Publication, Gen. issue agriculture, 2007)

Under such circumstances, the major objectives of the present study are

To assess the quality of perceived stress, stress- factors and also to quantify these.

To find some possible remedies for those workers in protecting them, at least, partially.

\section{Materials \& Methods}

\section{Data Collection}

Standardized and modified Nordic Questionnaire was employed to get the correlated data including socio-economic backgrounds, health status, activity profile, time spent, frequency of performance, total number of days performed in a year etc, for performing the harvest and post-harvest activities The present study is a community based double blind study, carried out in Golagori village, Khannan, Itachuna vllage, Talandu and Singur area, under the district of Hooghly, West Bengal. The population of the study comprised of the female workers of Khannan, Itachuna and Singur Hooghly, West Bengal who are involved in potato and paddy production.

\section{Selection of the Villages and Sample for the Study}

The female workers were randomly selected in a double blind manner for the study. The sample comprised of 95 female agricultural workers and 95 sedentary females $(n=190)$ from the said villages. Ethical clearance was procured from Institutional Ethics Committee (IEC-H) from Presidency University (erstwhile college). The subjects were divided into two groups, each of 95 subjects. 95 subjects were randomly assigned for Experimental group-A, who are involved with extensive field work for more than 5 years uninterrupted, whereas in Control group-B, another 95 samples, who are involved in other forms of sedentary work for equal tenure are taken into account. Both the groups belong to similar socioeconomic status. All the physical and performance cum physiological parameters were assessed and compared among these two groups.

\section{Procedure}

Various physical parameters were measured including height (by Anthropometric Rod), weight (by Weighing Machine), B.M.I, waist-hip ratio (by measuring tape) and blood pressure (by Sphygmomanometer). Other dynamic parameters were measured like Hand grip strength (by Hand grip Dynamometer, Jamar, USA), Pinch grip strength (by Pinch grip Dynamometer Jamar, USA) and Lung Function Test (by automatic Lung function machine \& software, Kokko, Finland) was also recorded. The bio-chemical parameters, i.e. blood glucose level was also measured by One- Touch Ultra Blood Glucose Monitor Kit (Johnson \& Johnson). Working postures like Ovako Working Posture analyses (OWAS), Rapid Upper Limb Assessment (RULA), Rapid Entire Body Assessment (REBA), Strain Index (SI Index) were evaluated by videoanalysis, with a standardized imported software, 'ERGOFELLOW, 2.0'. In order to compare the relation between various physical \& other dynamic parameters between the 
groups, statistical analysis was done using MINITAB 16 version, 2010.

\section{Results and Discussion}

Extensive statistical treatment of the data showed little deviation among the means of Height, Weight, BMI, Waist/Hip ratio and dynamic Lungs function parameters between the two comparable groups ensuring minute changes without any statistical significance.

The result of the study revealed that for experimental group, only systolic blood pressure (SBP) is found to be higher ( $\mathrm{p}<$ 0.05) compared to the control group. Student's t-test indicated Blood glucose level of the agricultural women were much lower than the control part $(\mathrm{p}<0.05)$. Also work station related ergonomically designed parameters: Ovako Working Posture analyses (OWAS), Rapid Upper Limb Assessment (RULA), Rapid Entire Body Assessment (REBA) and SI Index scores were markers of the awkward posture used due to their daily work and it indicated immediate corrective measure $(\mathrm{p}<0.05)$. (Fig 1-8), (Tab-1)

Woman is the backbone of agricultural workforce but worldwide her hard work has mostly been unpaid. Presently, they constitute one-third of the agricultural labour-force and about $48 \%$ of self employed farmers. Due to malnutrition and huge work load at home and field they suffer different kind of difficulties, causes WMSD. It might be mentioned as per the WHO guidelines for the Indian population, it was found that sawing and ploughing workers were under-weight in comparison to their normal counterparts.

The present study found that the ergonomically postural analyses like RULA, REBA, OWAS, SI scores were too high incase of exposed group. It means they compelled to follow awkward posture due to their working schedule and the score of particulars suggests that they need immediate corrective action otherwise the present condition of extensive suffering form body pain and WMSD will be further worsened and may impose complete inability in physical activities. It was also found that those working women have low blood glucose level. Since they are found to suffer from menstrual irregularities, polycystic ovaries and early menopause, it appears abnormal blood sugar and malnutrition would augment the sufferings further.

\begin{tabular}{|l|c|c|l|c|c|}
\hline \multicolumn{2}{|c|}{ Total Female Workers (WB) } & \multicolumn{4}{|c|}{ Categories of Main Workers } \\
\hline \multirow{2}{*}{} & & Cultivators & $\begin{array}{l}\text { Agricultural } \\
\text { Labourers }\end{array}$ & $\begin{array}{c}\text { Household } \\
\text { Industry }\end{array}$ & Other Workers \\
\cline { 3 - 6 } Rural & 5871301 & 584261 & 2671217 & 959286 & 1656537 \\
\hline Urban & 2169007 & 32386 & 64811 & 390155 & 1681655 \\
& & & & & \\
\hline
\end{tabular}


Int.J.Curr.Res.Aca.Rev.2016; 4(5): 155-166

Table.1 Level of Significance Showing Difference Between Exposed \& Control Group

\begin{tabular}{|c|c|c|c|}
\hline PARAMETERS & EXPOSED GROUP $(\mathrm{N}=95)$ & $\begin{array}{l}\text { CONTROL GROUP } \\
\qquad(\mathrm{N}=95)\end{array}$ & $\begin{array}{l}\text { P VALUE } \\
\quad<0.05\end{array}$ \\
\hline Height & 152.63 & 153.19 & 0.718 \\
\hline Weight & 48.25 & 49.13 & 0.089 \\
\hline B.M.I & 17.97 & 20.96 & 0.645 \\
\hline SBP & 135 & 118 & 0.011 \\
\hline DBP & 87.75 & 91 & 0.086 \\
\hline $\mathrm{W} / \mathrm{H}$ ratio & 0.845 & 0.915 & 0.095 \\
\hline FVC & 2.294 & 3.094 & 0.078 \\
\hline PEFR & 2.734 & 3.15 & 0.069 \\
\hline Blood glucose & 70.5 & 122.88 & $\mathbf{0 . 0 0 0}$ \\
\hline REBA & 12 & 4 & 0.000 \\
\hline RULA & 7 & 2.5 & 0.000 \\
\hline OWAS & 3 & 1.5 & 0.000 \\
\hline SI INDEX & 7 & 1 & 0.000 \\
\hline
\end{tabular}

Figure.1 Bar Diagram Represents Comparison of Height Between Women Agricultural \& Control Group.

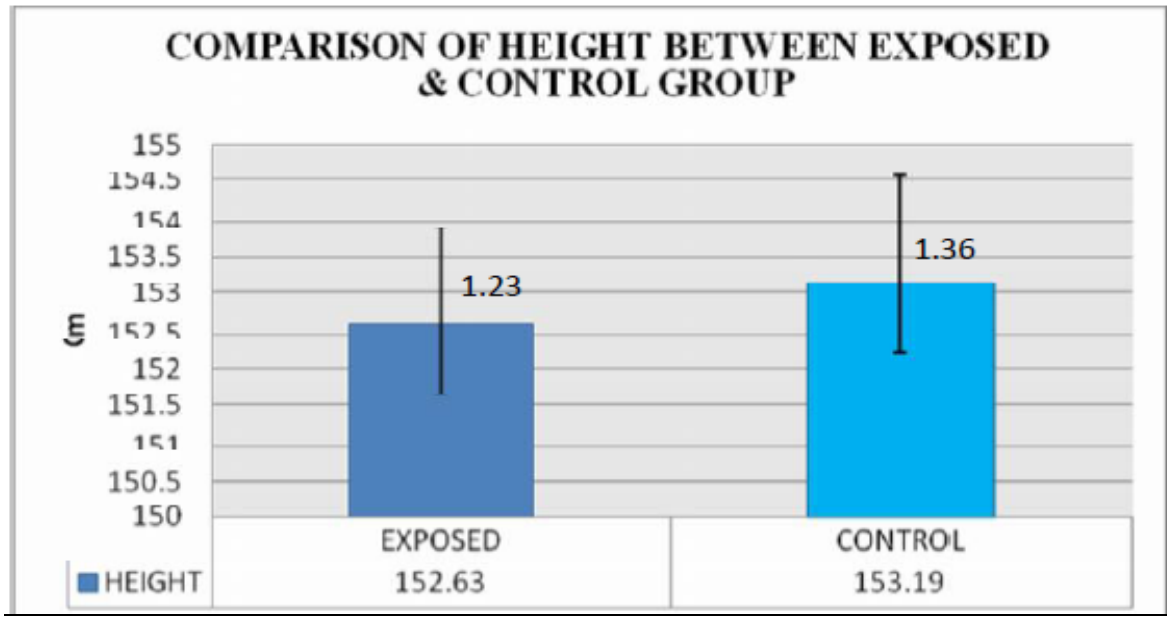


Int.J.Curr.Res.Aca.Rev.2016; 4(5): 155-166

Figure.2 Bar diagram represents comparison of weight between women agricultural \& control group.

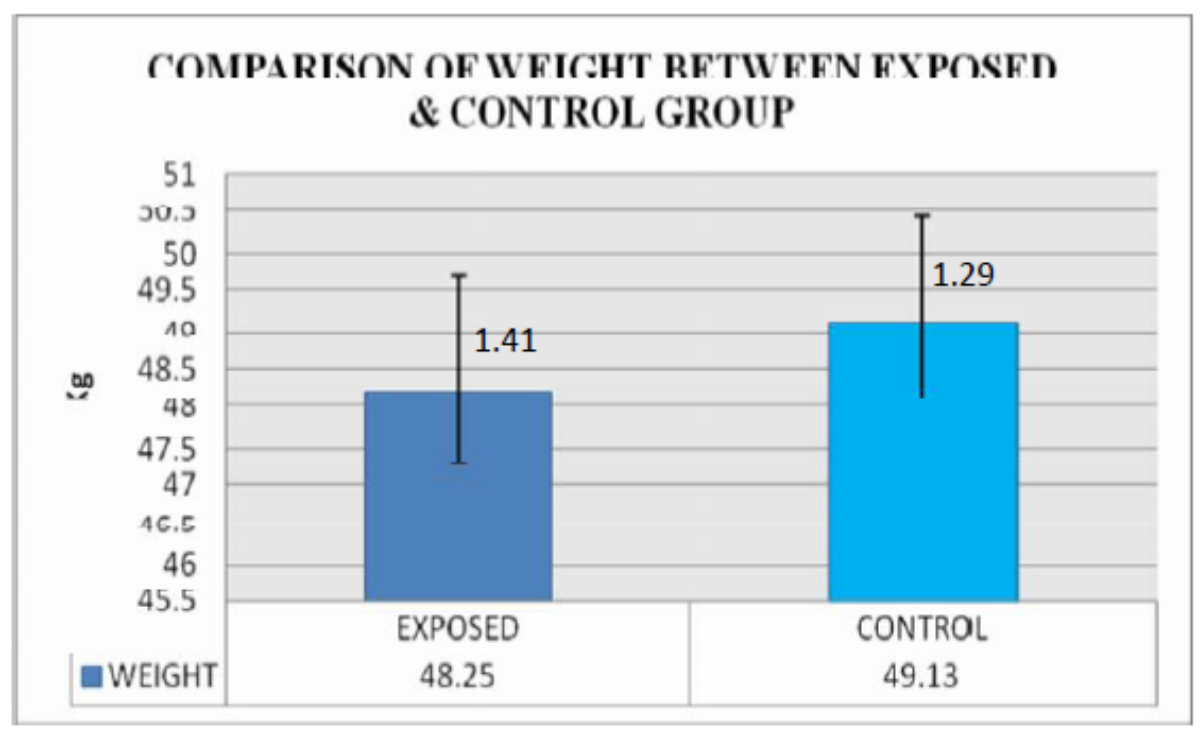

Figure.3 Bar diagram represents comparison of BMI between women agricultural \& control group.

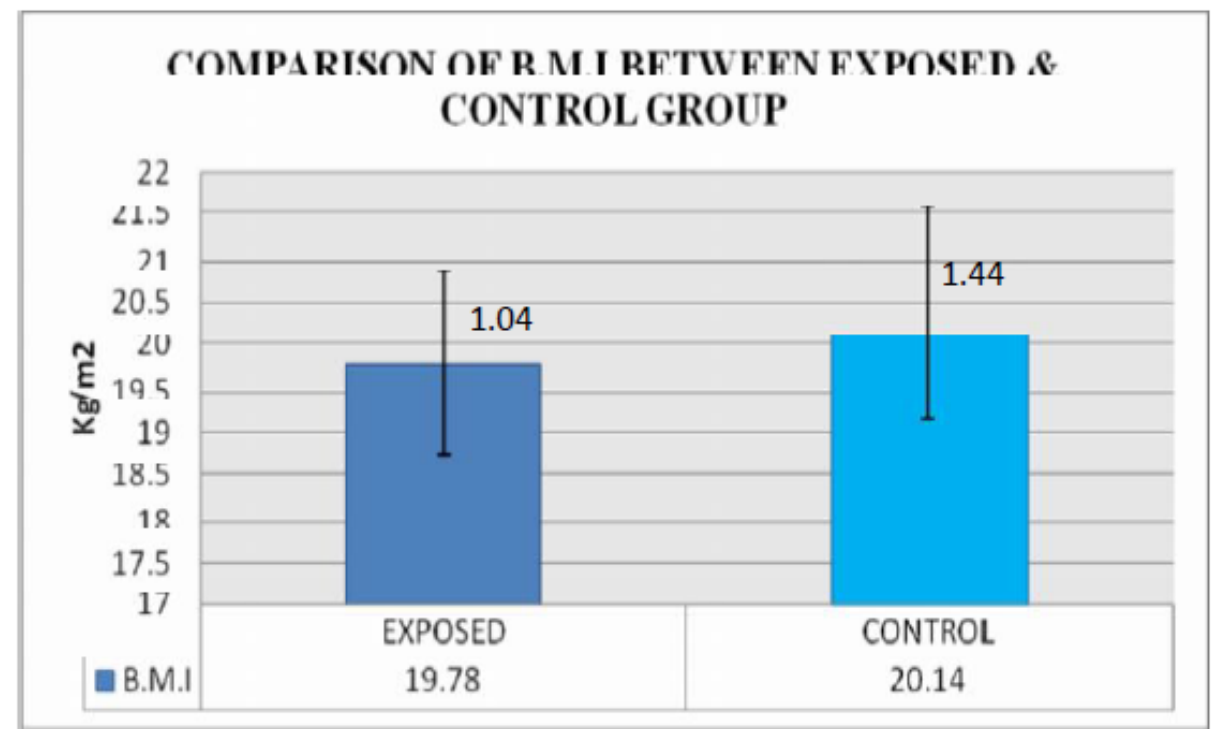


Int.J.Curr.Res.Aca.Rev.2016; 4(5): 155-166

Figure.4 Bar diagram represents comparison of SBP between women agricultural \& control group.

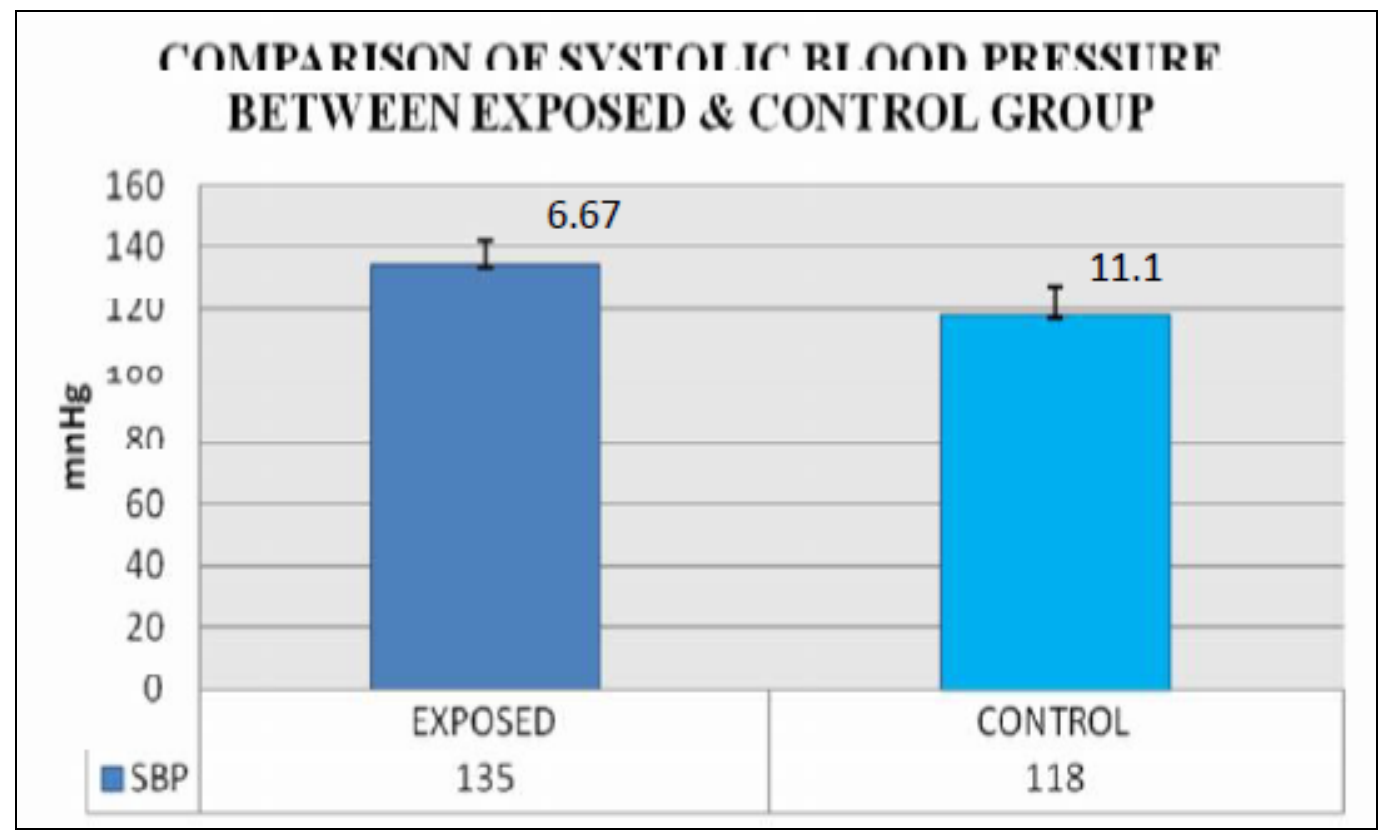

Figure.5 Bar diagram represents comparison of DBP between women agricultural \& control group.

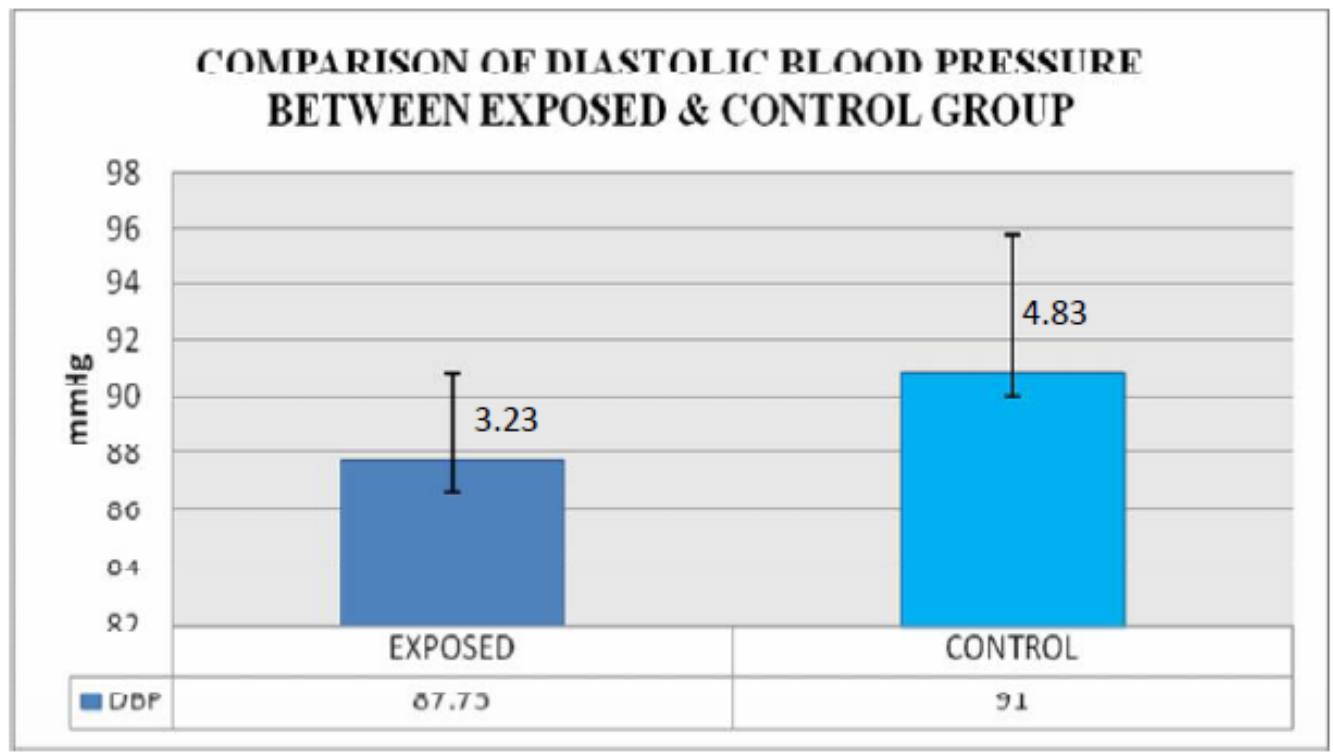


Int.J.Curr.Res.Aca.Rev.2016; 4(5): 155-166

Figure.6 Bar diagram represents comparison of $\mathrm{W} / \mathrm{H}$ ratio between women agricultural \& control group.

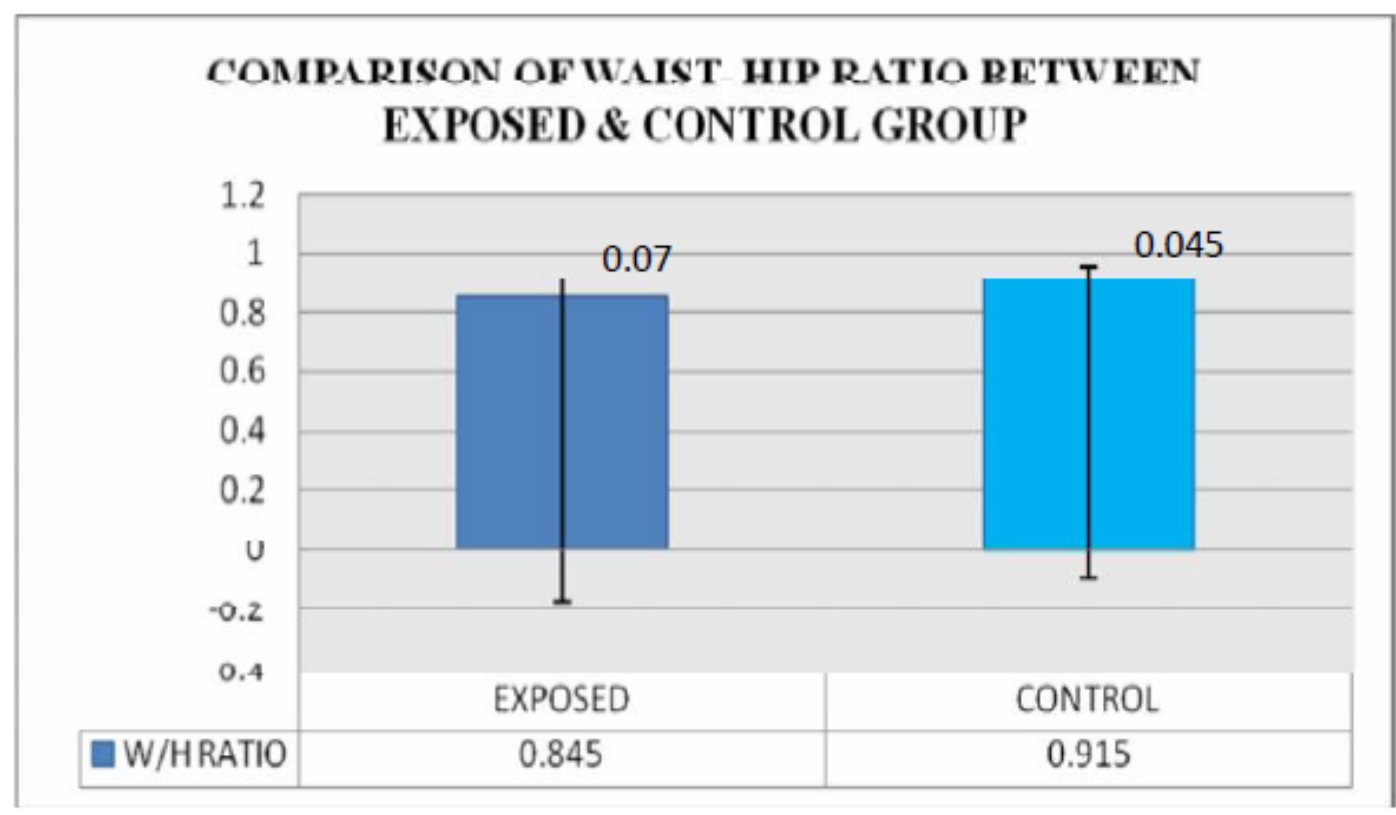

Figure.7 Bar diagram represents comparison of FVC between women agricultural \& control group

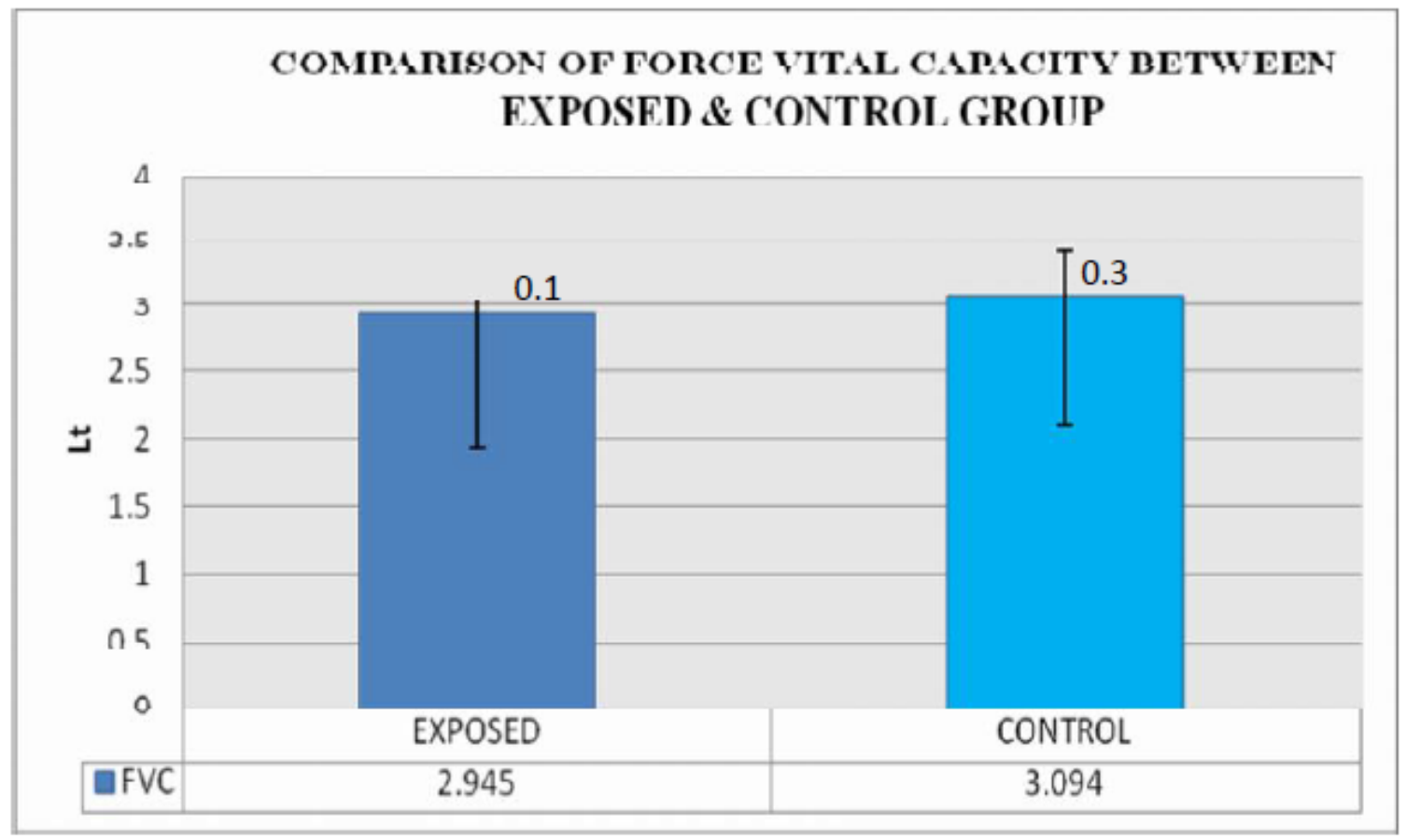


Int.J.Curr.Res.Aca.Rev.2016; 4(5): 155-166

Figure.8 Bar diagram represents comparison of PEFR between women agricultural \& control group

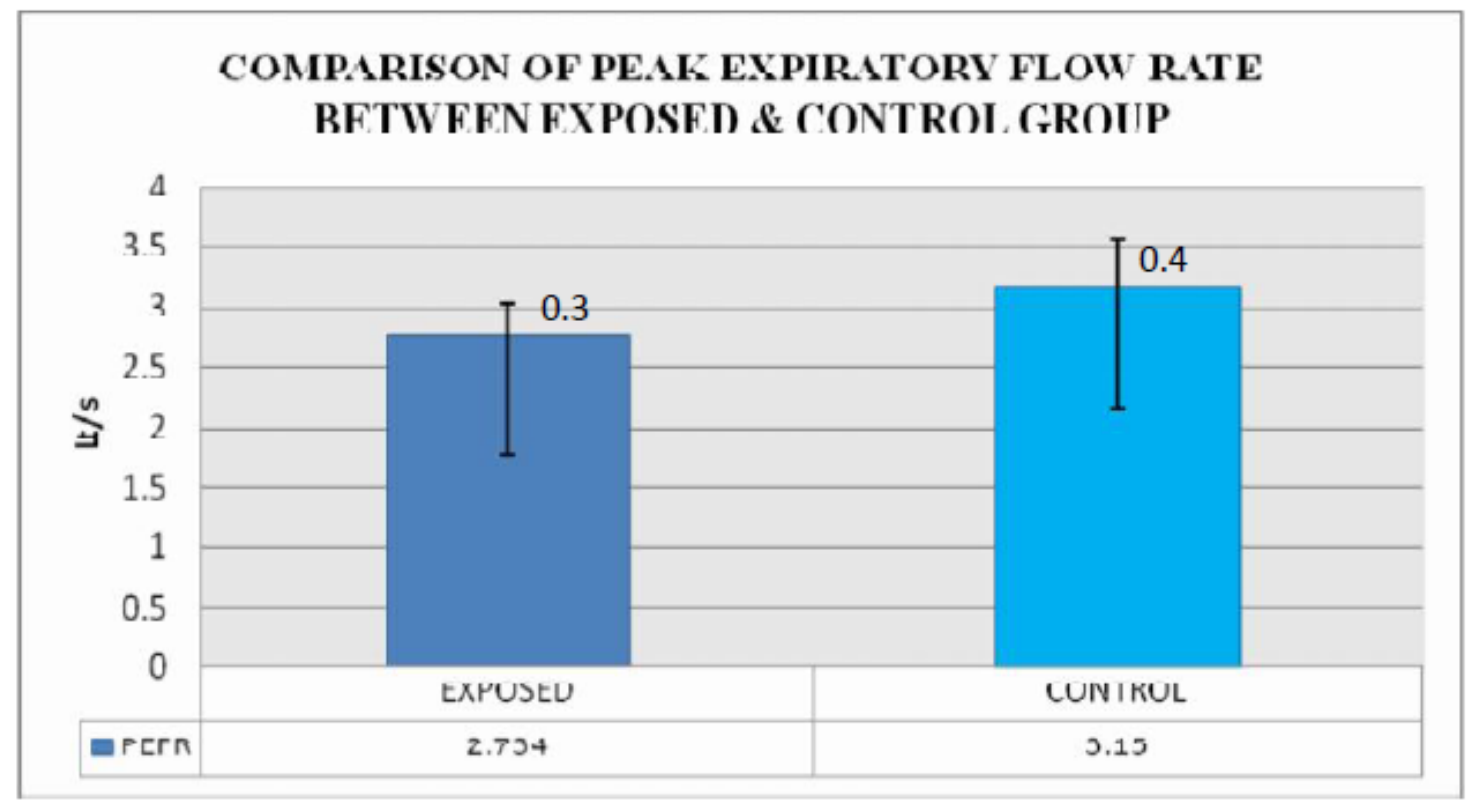

Figure.9 Bar diagram represents comparison of blood sugar between women agricultural \& control group

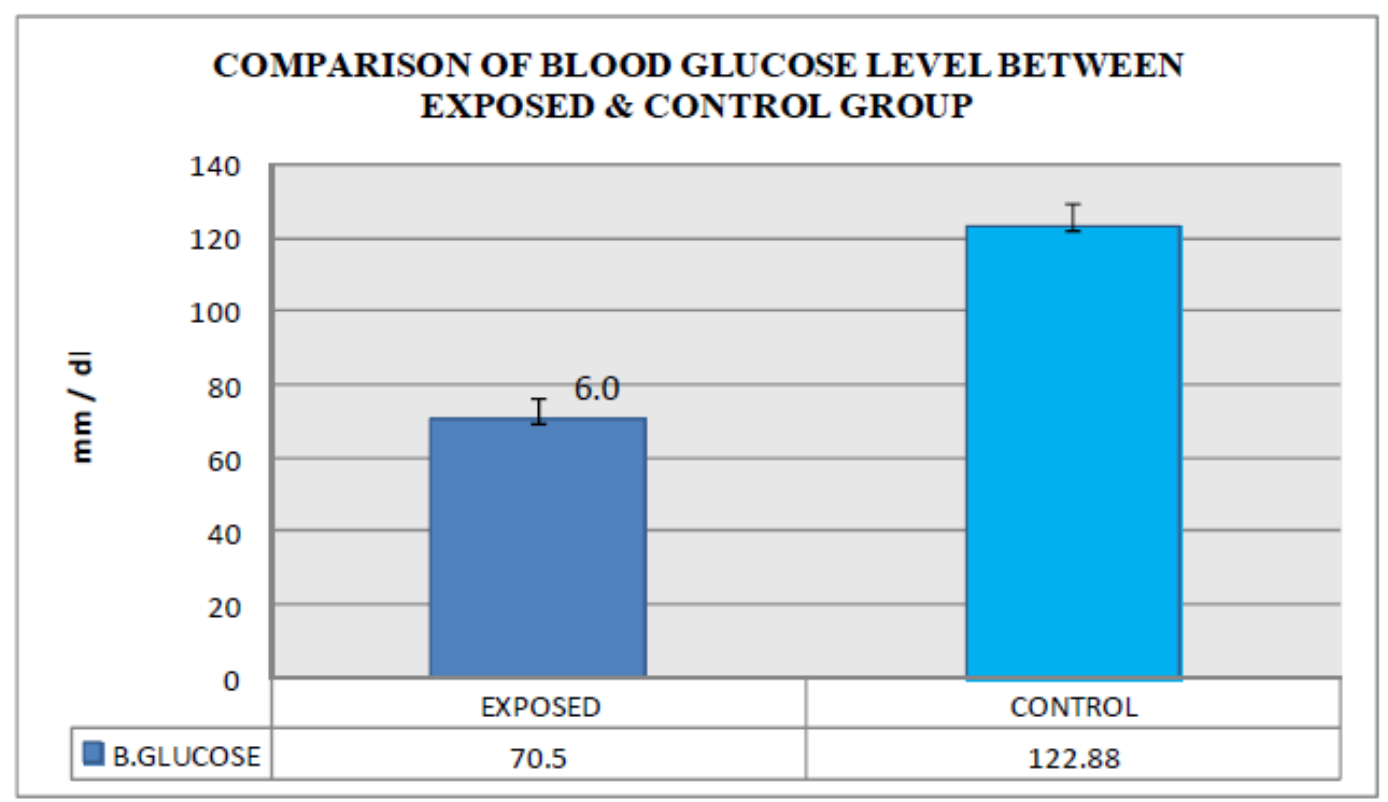


Int.J.Curr.Res.Aca.Rev.2016; 4(5): 155-166

Figure.10 Bar diagram represents comparison of REBA score between women agricultural \& control group.

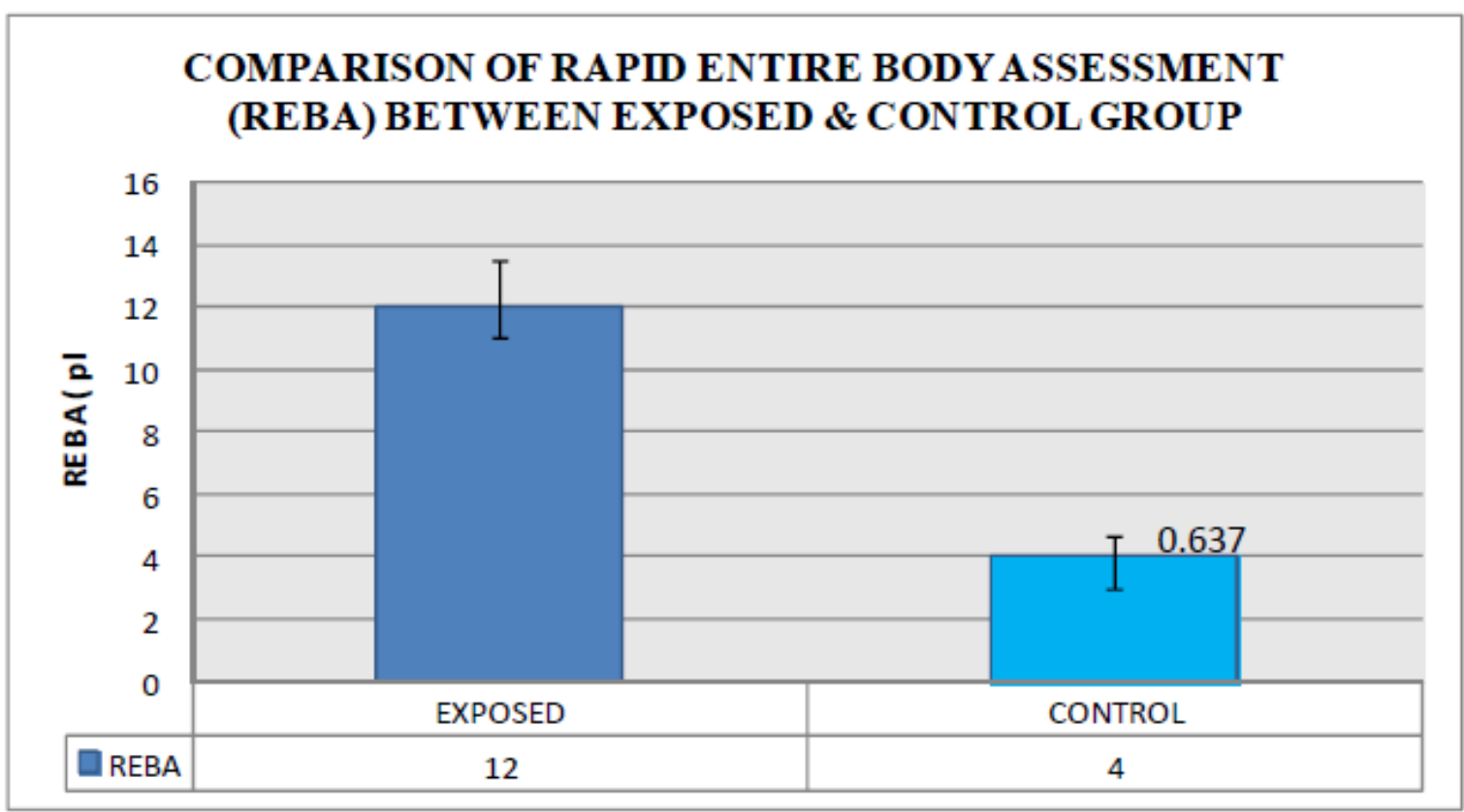

Figure.11 Bar diagram represents comparison of RULA score between women agricultural \& control group.

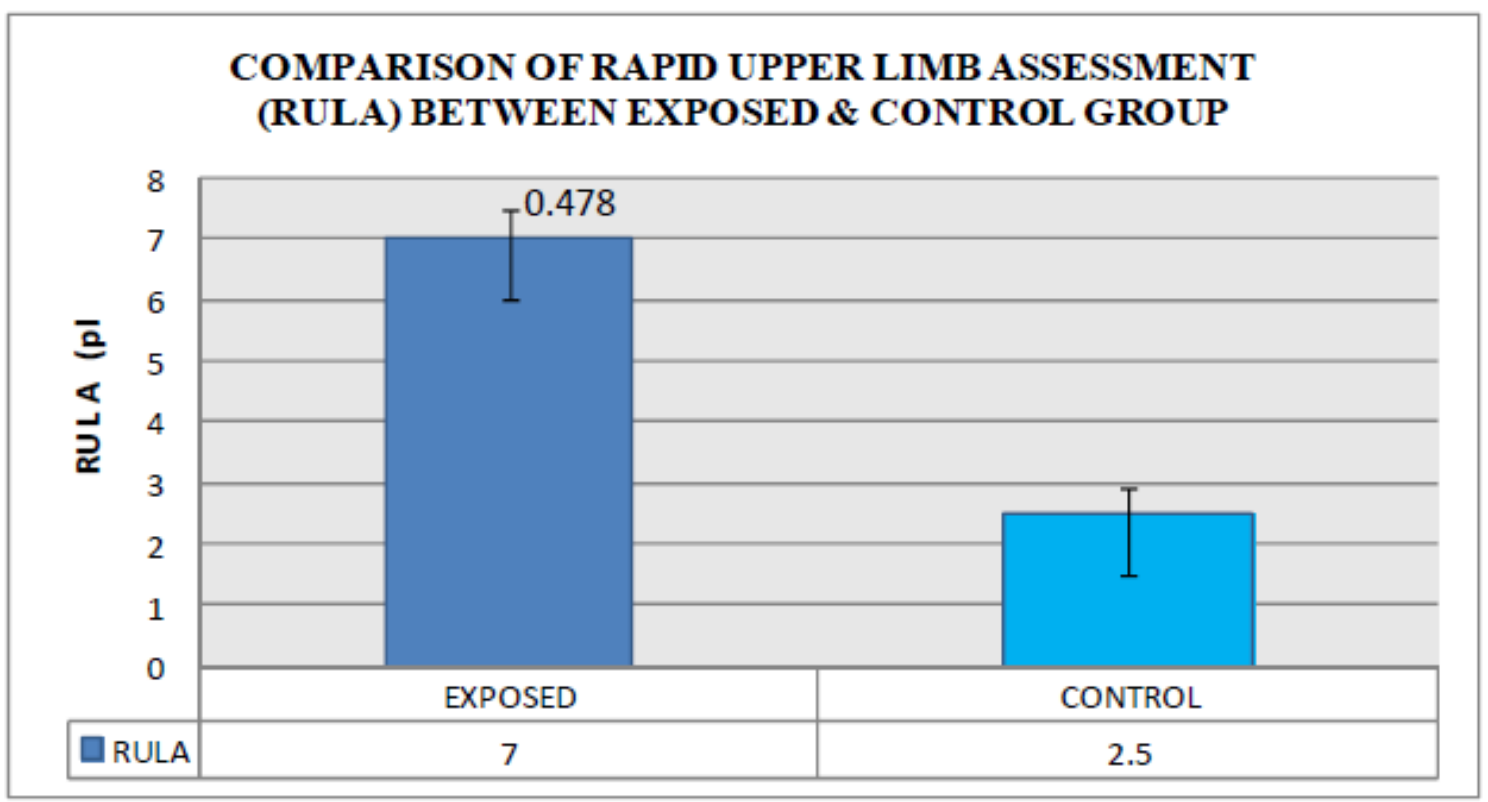


Int.J.Curr.Res.Aca.Rev.2016; 4(5): 155-166

Figure.12 Bar diagram represents comparison of OWAS score between women agricultural \& control group

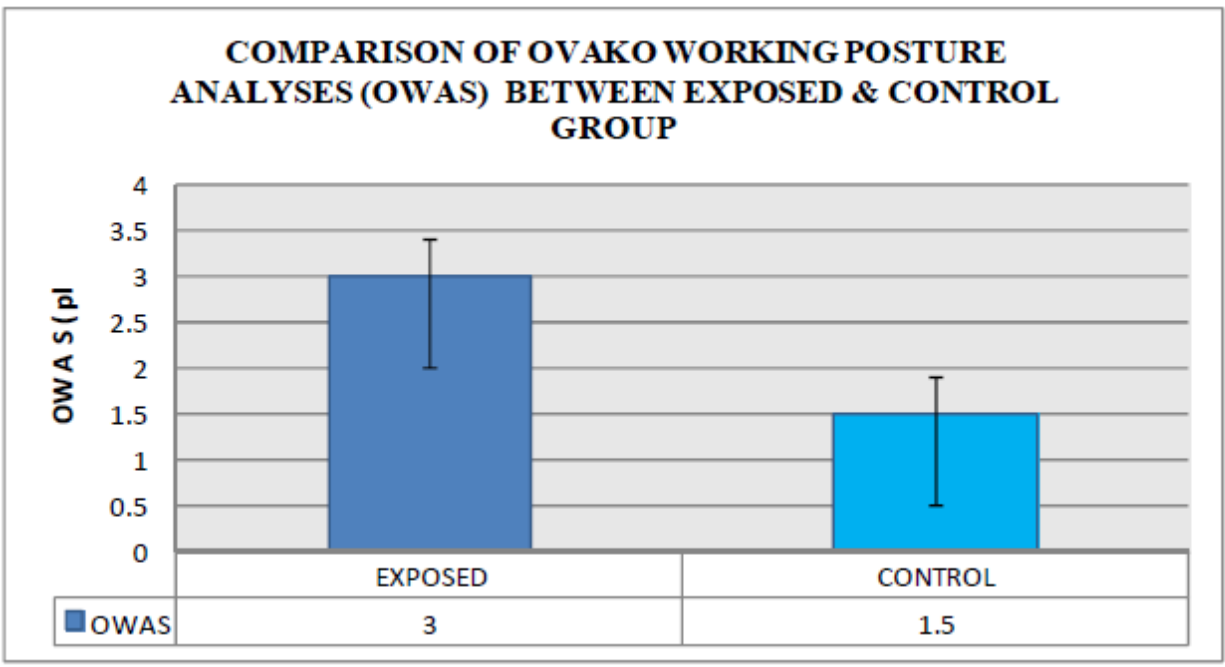

Figure.13 Bar diagram represents comparison of SI index between women agricultural \& control group.

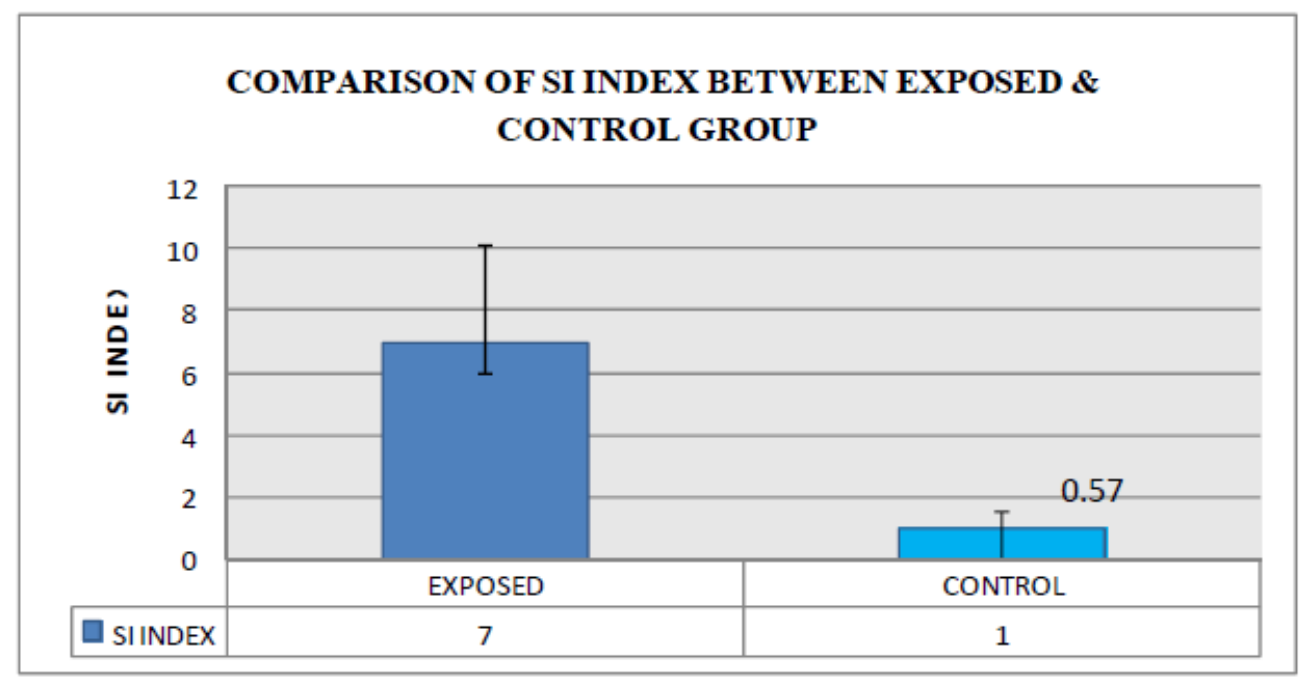

Hypoglycemia has multiple deleterious effects on various organ systems; including the heart, brain, and retina. Interestingly, in this study, the working women showed higher value in systolic blood pressure only. It means they might be suffering from Isolated Systolic Hypertension (ISH). ISH in mid-age suggest higher risk for having a heart attack, heart failure or a stroke. ISH can be caused by underlying conditions such as artery stiffness, heart valve problems or an overactive thyroid (hyperthyroidism).
When blood sugar drops, due to excess adrenalin secretion, bradicardia and sweating results. This physiological conditions present in this study showed similar characters amongst the experimental group, ensuring the impact of cumulative stress factors in altering the heart status with glucose level.

The maximum stipulated hours of work by Factories Act 1948 is 8 hours per day (Sarkar P, 2008) but the workers of the 
present study are found to work 10-12 hours as noticed by other scientist as well (Lakhani R, 2004). This affects their health and they are prone to accidents. Most of the agricultural sectors in India are unorganized, that could be another problem for women workers. So, various health hazards are associated with the agriculture industry by different awkward postures.

Farm workers incur various occupational related risk but they do not adequately compensated for facing that such risk. She also found that farm workers in India receive approx Rs.20/- per hour facing occupational health risk (P. Devi et al., 2012). Ultimately they suffered in work stress, social stress, family stress and personal stress, which affect their physiological condition. So, stress is the major factor that affects their health poorly.

Occupational hazards, excessive stress in work station, fault of work station design, environmental stressors, more hour spend over recommended time, lack of proper nutritional supplements etc are the most important factors that affects their health.

Woman has different ergonomically characteristics than man. So, design of women friendly tools and equipment is required for reducing these health hazards.

\section{Acknowledgement}

We were indebted and to convey my deepest sense of gratitude and sincere appreciation to all the villagers of Golagori, Itachuna,
Singur for their cooperation and help. The female farmers of that village are the most important part of that work, without them this cannot be possible for us.

\section{References}

Gender Issues in Agriculture Labors. 2007Module 8. World Bank Publication.

Lakhani, R. 2004. Occupational Health of women construction workers in the unorganized sector, Sage Journals Online, J. Health Manag., 6: 187-200.

Ministry of Labour \& Employment. 2013. Labor Bureau Chandigarh/shimla Government of India, ISSN 00195723, Indian Labor Journal, 54. No$7 \&$ 9, July \& Sept 2013.

Indira Devi, P., Shanmugam, K.R., Jayasree, M.G. 2012. Compensating Wages for Occupational Risks of Farm Workers in India, EconPapers-Working Paper71, Madras School of Economics, Chennai, India.

Sarkar, P. 2008. Working hours of adults; Factories Act, 1948 with Short Notes, 6: A35.

Vetrivel, V., Manigandan, R. 2013. An empirical study of agricultural labour in India. J. Exclusive Management Sci., Vol 2 Issue 12, ISSN 2277-5684.

Vijay Kumar Manwani, Sachin Pandey. 2013. Study of the Chemical Related Occupational Health Hazards Amongst Agricultural Workers in the Rural Area of Maharashtra, India; Indian J. Res., Vol:2 | Issue : 12. ISSN $-2250-1991$

\section{How to cite this article:}

Sugata Das, Anandi Bagchi, Somnath Gangopadhay and Subrata Ghosh. 2016. Work Related Health Disorders of Female Agricultural Workers Correlated with Sawing and Ploughing in Bengal: An Ergonomic Profile. Int.J.Curr.Res.Aca.Rev.4(5): 155-166. doi: http://dx.doi.org/10.20546/ijcrar.2016.405.015 